\title{
Radiation Effects on MHD Flow past an Exponentially Accelerated Isothermal Vertical Plate with Uniform Mass Diffusion in the Presence of Heat Source
}

\author{
P. Bala Anki Reddy ${ }^{1 \dagger}$, N. Bhaskar Reddy ${ }^{2}$ and S. Suneetha ${ }^{3}$ \\ ${ }^{1}$ Fluid Dynamics Division, VIT University, Vellore, Tamil Nadu-632014 \\ ${ }^{2}$ Department of Mathematics, N.B.K.R.I.S.T., Vidyanagar, Nellore - 524413, A.P., INDIA \\ ${ }^{3}$ Department of Mathematics, Y.S.R. Engineering College of Y.V.U., Proddatur, A.P., INDIA \\ †Corresponding Author Email: pbarmaths@gmail.com
}

(Received April 22, 2010; accepted March 6, 2011)

\begin{abstract}
The radiation effects on unsteady flow of a viscous incompressible fluid past an exponentially accelerated infinite isothermal vertical plate with uniform mass diffusion is considered in the presence of magnetic field and heat source. The governing partial differential equations are converted into a non-dimensional form and solved numerically by applying a Crank-Nicholson type of implicit finite difference method with a tri-diagonal matrix manipulation and an iterative procedure. The profiles of unsteady velocity, temperature and concentration are shown graphically for different values of thermo physical parameters. Also, the simulated values of the skin-friction coefficient, Nusselt number and Sherwood number are presented. This model finds applications in solar energy collection systems, geophysics and astrophysics, aero space and also in the design of high temperature chemical process systems.
\end{abstract}

Keywords: Radiation, MHD, Mass diffusion, Heat source, Isothermal vertical plate.

\section{INTRODUCTION}

Natural convection induced by the simultaneous action of buoyancy forces from thermal and mass diffusion is of considerable interest in many industrial applications such as geophysics, oceanography, drying processes and solidification of binary alloy. Eckert and Drake (1972) have done pioneering work on heat and mass transfer. Gebhart et al. (1998) studied the natural convection boundary layer flow due to simultaneous heat and mass transfer with various geometries. The effects of foreign masses, also known as diffusing species concentration, were studied under different conditions by Somers (1956), Mathers et al. (1957) and others either by integral method or by asymptotic analysis. But first systematic study of mass transfer effects on free convection flow past a semi-infinite plate was presented by Gebhart and Pera (1971). Soundalgekar and Ganesan (1981) studied transient free convective flow past a semi-infinite vertical flat plate with mass transfer by using Crank-Nicholson finite difference method. Gupta et al. (1979) studied free convection flow past a linearly accelerated vertical plate in the presence of viscous dissipative heat using perturbation method. Kafousias and Raptis (1981) extended this problem to include mass transfer effects subjected to variable suction or injection. Free convection effects on flow past an exponentially accelerated vertical plate was studied by Singh and Naveen Kumar (1984). Basant Kumar Jha et al. (1991) analyzed mass transfer effects on exponentially accelerated infinite vertical plate with constant heat flux and uniform mass diffusion. Recently Muthucumaraswamy et al. (2006) studied mass transfer effects on exponentially accelerated isothermal vertical plate.

The study of flow problems, which involve the interaction of several phenomena, has a wide range of applications in the field of science and technology. One such study is related to the effects of MHD free convection flow, which plays an important role in agriculture, engineering and petroleum industries. The problem of free convection under the influence of magnetic field has attracted the interest of many researchers in view of its application in geophysics and astrophysics. Kim (2000) investigated unsteady MHD convective heat transfer past a semi-infinite vertical porous moving plate with variable suction by assuming that the free stream velocity follows the exponentially increasing small perturbation law. Gribben (1965) studied boundary layer flow over a semi-infinite vertical plate with an aligned magnetic field in the presence of a pressure gradient. $\mathrm{He}$ obtained solutions for large and small magnetic Prandtl numbers using the method of matched asymptotic expansion. Helmy studied 
magnetohydrodynamic unsteady free convection flow past a vertical porous plate. Elbashbeshy (1997) studied heat and mass transfer along a vertical plate under the combined buoyancy effects of thermal and species diffusion, in the presence of the magnetic field.

In many situations there may be an appreciable temperature difference between the surface and ambient fluid. These necessities the consideration of temperature dependent heat sources or sinks which may exert strong influence on the heat transfer characteristics. The study of heat generation or absorption in moving fluids is important in view of several physical problems, such as fluids under going exothermic or endothermic chemical reactions. Representative studies dealing with these effects have been reported by Vajravelu and Hadijinicolaou (1993) and Chamkha (1997). Pop and Soundalgekar (1962) studied unsteady free convection flow past an infinite plate with constant suction and heat source. Suneetha et al. (2011) investigated radiation and mass transfer effects on MHD free convective dissipative fluid in the presence of heat source/ sink. More recently Takhar et al. (1986) presented one of the most robust studies of thermal and concentration boundary layers with MHD effects for the case of a point sink. Sahoo et al. (2003) studied magnetohydrodynamic unsteady free convection flow past an infinite vertical plate with constant suction and heat sink.

In space technology processes involving high temperature flows, the effects of radiation are of vital importance. Recent developments in hypersonic flights, missile re-entry, rocket combustion chambers, power plants for inter planetary flight and gas cooled nuclear reactors, have focused attention on thermal radiation as a mode of energy transfer, and emphasized the need for improved understanding of radiative transfer in these processes. Soundalgekar and Takhar (1993) considered the radiative free convective flow of an optically thin gray-gas past a semi-infinite vertical plate. Radiation effects on mixed convection along an isothermal vertical plate were studied by Hossain and Takhar (1996). Raptis and Perdikis (1999) studied the effects of thermal radiation and free convection flow past a moving vertical plate. Das et al. (1996) analyzed radiation effects on flow past an impulsively started infinite isothermal vertical plate. Muthucumaraswamy and Janakiraman (2006) studied MHD and radiation effects on moving isothermal vertical plate with variable mass diffusion. Ramachandra Prasad et al. (2006) analyzed the radiation effects on MHD free convection flow with mass transfer past a semiinfinite vertical plate in the presence of heat source/sink.

However, the interaction of radiation with mass transfer past an accelerated isothermal vertical plate with uniform mass diffusion in the presence of magnetic field and heat source has received little attention. Hence an attempt is made to analyze the radiation and mass transfer effects on hydromagnetic flow past an accelerated isothermal vertical with uniform mass diffusion in the presence of heat source. The equations of continuity, linear momentum, energy and diffusion, which govern the flow field, are solved by an implicit finite difference method of Crank-Nicolson type. The behavior of the velocity, temperature, concentration, skin-friction, Nusselt number and Sherwood number has been discussed for a range of physical parameters.

\section{Mathematical Analysis}

An unsteady two-dimensional flow of a viscous incompressible electrically conducting and radiating fluid past an exponentially accelerated infinite isothermal vertical plate with uniform mass diffusion is considered. A temperature dependent heat source is assumed to be present in the flow. The fluid is assumed to be gray, absorbing-emitting but nonscattering. Initially the fluid is assumed to be at rest and surrounds an infinite vertical plate with temperature $T_{\infty}$ and concentration $C_{\infty}^{\prime}$. The $x$-axis is taken along the plate in the vertically upward direction and the $y$-axis is taken normal to the plate.

At time $t^{\prime} \leq 0$, the plate and fluid are at the same temperature $T_{\infty}$ and concentration $C_{\infty}^{\prime}$. At time $t^{\prime}>0$, the plate is exponentially accelerated with a velocity $u=u_{0} e^{a^{\prime} t^{\prime}}$ in its own plane and the plate temperature and concentration are raised to $T_{w}$ and $C_{w}^{\prime}$ and are maintained constantly thereafter. A uniform magnetic field is applied in the direction perpendicular to the plate. The transverse applied magnetic field and magnetic Reynolds number are assumed to be such small, so that the induced magnetic field can be neglected. It is assumed that the concentration $C^{\prime}$ of the diffusing species in the binary mixture is very less in comparison to the other chemical species, which are present, and hence the Soret and Dufour effects are negligible (Ramachandra Prasad et al. 2007).

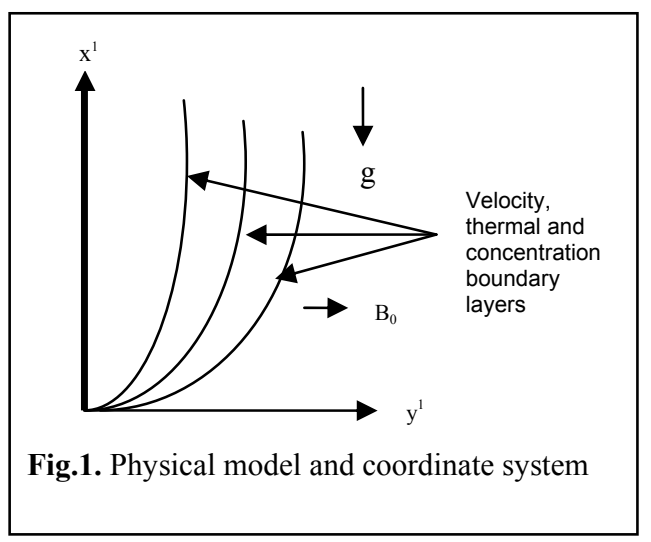

It is also assumed that there is no chemical reaction between the diffusing species and the fluid. Then, under the usual Boussinesq's approximation, in the absence of an input electric field, the governing boundary layer Eqs. are

$\frac{\partial u}{\partial t^{\prime}}=g \beta\left(T-T_{\infty}\right)+g \beta^{*}\left(C^{\prime}-C_{\infty}^{\prime}\right)+v \frac{\partial^{2} u}{\partial y^{2}}-\frac{\sigma B_{0}^{2}}{\rho} u$ 
$\rho C_{p} \frac{\partial T}{\partial t^{\prime}}=k \frac{\partial^{2} T}{\partial y^{2}}-\frac{\partial q_{r}}{\partial y}+Q_{0}\left(T-T_{\infty}\right)$

$\frac{\partial C^{\prime}}{\partial t^{\prime}}=D \frac{\partial^{2} C^{\prime}}{\partial y^{2}}$

The initial and boundary conditions are

$t^{\prime} \leq 0: u=0, T=T_{\infty}, C^{\prime}=C_{\infty}^{\prime}$ for all $y$

$t^{\prime}>0: u=u_{0} e^{a^{\prime} t^{\prime}}, T=T_{w}, C^{\prime}=C_{w}^{\prime}$ at $y=0$

$u \rightarrow 0, T \rightarrow T_{\infty}, C^{\prime} \rightarrow C_{\infty}^{\prime}$ as $y \rightarrow \infty$

where $u$ is the velocity component in $x$ direction, $t^{\prime}$ - the time, $\mathrm{g}$-the acceleration due to gravity, $\beta$ the volumetric coefficient of thermal expansion, $\beta^{*}$ the volumetric coefficient of expansion with concentration, $T$-the temperature of the fluid in the boundary layer, $T_{\infty}$ - the free stream temperature far away from the plate, $C^{\prime}$ - the species concentration in the boundary layer, $C_{\infty}^{\prime}$ - the free stream concentration far away from the plate, $v$ - the kinematic viscosity, $\sigma$ - the electrical conductivity, $B_{0}$ - the magnetic induction, $\rho$ - the density of the fluid, $c_{p}$ - the specific heat at constant pressure, $k$ the thermal conductivity, $q_{r}$ - the radiation heat flux, $Q_{0}$ - the heat generation/absorption and $D$ - the species diffusion coefficient.

The local radiation for the case of an optically thin gray gas is expressed as

$\frac{\partial q_{r}}{\partial y}=-4 a^{*} \sigma\left(T_{\infty}^{4}-T^{4}\right)$

where $a^{*}$ is the absorption coefficient and $\sigma$ - the electric conductivity. It is assumed that the temperature differences with in the flow are sufficiently small, so that $T^{4}$ may be expressed as a linear function of the temperature. This is accomplished by expanding $T^{4}$ in a Taylor series about $T_{\infty}$ and neglecting the higher order terms, thus

$T^{4} \cong 4 T_{\infty}^{3} T-3 T_{\infty}^{4}$

By using Eqs. (4) and (5), Eq. (2) reduces to

$$
\begin{aligned}
\rho c_{p} \frac{\partial T}{\partial t^{\prime}} & =k \frac{\partial^{2} T}{\partial y^{2}}+16 a^{*} \sigma T_{\infty}^{3}\left(T_{\infty}-T\right) \\
& +Q_{0}\left(T-T_{\infty}\right)
\end{aligned}
$$

On introducing the following non-dimensional quantities

$$
\begin{aligned}
& U=\frac{u}{u_{0}}, t=\frac{t^{\prime} u_{0}^{2}}{v}, Y=\frac{y u_{0}}{v}, \\
& G r=\frac{v g \beta\left(T_{w}^{\prime}-T_{\infty}^{\prime}\right)}{u_{0}^{3}}, \\
& G m=\frac{v g \beta^{*}\left(C_{w}^{\prime}-C_{\infty}^{\prime}\right)}{u_{0}^{3}}, \\
& \theta=\frac{T-T_{\infty}}{T_{w}^{\prime}-T_{\infty}} \quad C=\frac{C^{\prime}-C_{\infty}^{\prime}}{C_{w}^{\prime}-C_{\infty}^{\prime}},
\end{aligned}
$$

$$
\begin{aligned}
& \operatorname{Pr}=\frac{\mu c_{p}}{k}, S c=\frac{v}{D}, M=\frac{\sigma B_{0}^{2} v}{u_{0}^{2}}, \\
& R=\frac{16 a^{*} v^{2} \sigma T_{\infty}^{3}}{k u_{0}^{2}}, \varphi=\frac{Q_{0} v}{\rho c_{p} u_{0}^{2}}, a=\frac{a^{\prime} v}{u_{0}^{2}}
\end{aligned}
$$

The Eqs. (1), (7) and (4) reduce to

$$
\begin{aligned}
& \frac{\partial U}{\partial t}=G r \theta+G m C+\frac{\partial^{2} U}{\partial Y^{2}}-M U \\
& \frac{\partial \theta}{\partial t}=\frac{1}{\operatorname{Pr}} \frac{\partial^{2} \theta}{\partial Y^{2}}-\frac{R}{\operatorname{Pr}} \theta+\varphi \theta \\
& \frac{\partial C}{\partial t}=\frac{1}{S c} \frac{\partial^{2} C}{\partial Y^{2}}
\end{aligned}
$$

where $G r, G m, M, P r, R, \phi$ and $S c$ are thermal Grashof number, mass (solutal) Grashof number, magnetic parameter, Prandtl number, radiation parameter, the dimensionless heat generation/absorption coefficient and Schmidt number respectively.

The corresponding initial and boundary conditions are

$$
\begin{aligned}
& t \leq 0: U=0, \theta=0, C=0 \text { for all } Y \\
& t>0: U=e^{a t}, \theta=1, C=1 \text { at } Y=0 \\
& U \rightarrow 0, \theta \rightarrow 0, C \rightarrow 0 \text { as } Y \rightarrow \infty
\end{aligned}
$$

\section{Solution of the Problem}

The governing Eqs. (9)-(11) represent coupled system of non-linear partial differential equations, which are solved numerically under the initial and boundary conditions (12) using Crank-Nicolson implicit finite difference scheme, which is always unconditionally stable. To obtain the difference equations, the region of the flow is divided into a grid or mesh lines parallel to $y$ and $t$ axes.

Solutions of difference equations are obtained at the intersection of these mesh lines called nodes. The values of the dependent variables $C, \theta$ and $U$ at the nodal points along the $y=0$ are given by $C(0, t)$, $\theta(0, t)$ and $U(0, t)$, hence are known from the boundary conditions. $\Delta y, \Delta t$ are taken as the constant mesh sizes along $y$ and $t$ directions respectively. We need a scheme to find single values at next time level in terms of known values at an earlier time level.

A forward difference approximation for the first order partial derivatives of $C, \theta$ and $U$ with respect to $t$ and $y$ and a central difference approximation for the second order partial derivatives of $\mathrm{C}, \theta$ and $\mathrm{U}$ with respect to y are used.

The finite difference equations corresponding to Eqs. (9) - (11) are as follows 


$$
\begin{aligned}
& \frac{\left[U_{i, j}^{n+1}-U_{i, j}^{n}\right]}{\Delta t} \\
& =\frac{\left[U_{i, j-1}^{n+1}-2 U_{i, j}^{n+1}+U_{i, j+1}^{n+1}+U_{i, j+1}^{n+1}-2 U_{i, j}^{n}+U_{i, j+1}^{n}\right]}{2(\Delta Y)^{2}} \\
& \quad+G r \frac{\left[\theta_{i, j}^{n+1}+\theta_{i, j}^{n}\right]}{2}+G m \frac{\left[\theta_{i, j}^{n+1}+\theta_{i, j}^{n}\right]}{2} \\
& \quad-M \frac{\left[U_{i, j}^{n+j}+U_{i, j}^{n}\right]}{2} \\
& \frac{\left[\theta_{i, j}^{+1}-\theta_{i, j}^{i}\right]}{\Delta t} \\
& =\frac{1}{\operatorname{Pr}} \frac{\left[\theta_{i, j-1}^{n+1}-2 \theta_{i, j}^{++1}+\theta_{i, j+1}^{n+1}+\theta_{i, j-1}^{n}-2 \theta_{i, j}^{n}+\theta_{i, j+1}^{n}\right]}{2(\Delta Y)^{2}} \\
& -\frac{R}{\operatorname{Pr}}\left[\frac{\left.\theta_{i, j}^{n+1}+\theta_{i, j}^{n}\right]}{2}\right]+\varphi\left[\frac{\theta_{i, j}^{n+1}+\theta_{i, j}^{n}}{2}\right] \\
& \frac{\left[C_{i, j}^{n+1}-C_{i, j}^{n}\right]}{\Delta t} \\
& =\frac{1}{S c} \frac{\left[C_{i, j-1}^{n+1}-2 C_{i, j}^{n+1}+C_{i, j+1}^{n+1}+C_{i, j-1}^{n}-2 C_{i, j}^{n}+C_{i, j+1}^{n}\right]}{2(\Delta Y)^{2}}
\end{aligned}
$$

The Eqs. (13), (14) and (15) can be written as

$$
\begin{aligned}
& A_{1} U_{i-1, j+1}+B_{1} U_{i, j+1}-C_{1} U_{i+1, j+1}=E_{1} \\
& A_{2} \theta_{i-1, j+1}+B_{2} \theta_{i, j+1}-C_{2} \theta_{i+1, j+1}=E_{2} \\
& A_{3} C_{i-1, j+1}+B_{3} C_{i, j+1}-C_{3} C_{i+1, j+1}=E_{3}
\end{aligned}
$$

where

$$
\begin{aligned}
& A_{1}=-\frac{1}{2(\Delta y)^{2}}, B_{1}=\frac{1}{\Delta t}+\frac{1}{(\Delta y)^{2}}+\frac{M}{2}, \\
& C_{1}=-\frac{1}{2(\Delta y)^{2}} \\
& E_{1}=-\frac{1}{2(\Delta y)^{2}} U_{i-1, j}+\left[\frac{1}{\Delta t}-\frac{1}{(\Delta y)^{2}}-\frac{M}{2}\right] U_{i, j} \\
& +\frac{1}{2(\Delta y)^{2}} U_{i+1, j}+G r\left[\frac{\theta_{i, j+1}+\theta_{i, j}}{2}\right] \\
& A_{2}=-\frac{1}{2 \operatorname{Pr}(\Delta y)^{2}} \\
& B_{2}=\frac{1}{\Delta t}+\frac{1}{\operatorname{Pr}(\Delta y)^{2}}+\frac{R}{2 \operatorname{Pr}}-\frac{\varphi}{2} \\
& C_{2}=-\frac{1}{2 \operatorname{Pr}(\Delta y)^{2}} \\
& E_{2}=-\frac{1}{2 \operatorname{Pr}(\Delta y)^{2}} \theta_{i-1, j} \\
& +\left[\frac{1}{\Delta t}-\frac{1}{\operatorname{Pr}(\Delta y)^{2}}-\frac{R}{2 \operatorname{Pr}}+\frac{\varphi}{2}\right] \theta_{i, j}+\frac{1}{2 \operatorname{Pr}(\Delta y)^{2}} \theta_{i+1, j}
\end{aligned}
$$

$$
\begin{aligned}
& A_{3}=-\frac{1}{2 S c(\Delta y)^{2}}, B_{3}=\frac{1}{\Delta t}+\frac{1}{S c(\Delta y)^{2}} \\
& C_{3}=-\frac{1}{2 S c(\Delta y)^{2}} \\
& E_{3}=-\frac{1}{2 S c(\Delta y)^{2}} C_{i-1, j} \\
& +\left[\frac{1}{\Delta t}-\frac{1}{S c(\Delta y)^{2}}\right] C_{i, j}+\frac{1}{2 S c(\Delta y)^{2}} C_{i+1, j}
\end{aligned}
$$

Here the suffix $i$ corresponds to y and $j$ corresponds to $t$. Also $\Delta t=t_{j+1}-t_{j}$ and $\Delta y=y_{j+1}-y_{j}$.

Knowing the values of $\mathrm{C}, \theta$ and $\mathrm{U}$ at time $t$, we can calculate the values at a time $t+\Delta t$ as follows. We substitute $i=1,2, \ldots, M-1$ in Eq. (15) which results in a tri-diagonal system of equations in unknown values of C. Using initial and boundary conditions, the system can be solved by Gauss elimination method. Thus $\mathrm{C}$ is known for all values of $\mathrm{y}$ at time $t+\Delta t$. Then knowing the values of $\mathrm{C}$ and applying the same procedure and using boundary conditions, we calculate $\theta$ and $\mathrm{U}$ from Eqs.(14) and (13). This procedure is continued to obtain the solution till desired time t. The steady-state solution is assumed to have been reached, when the absolute difference between the values of $U$ as well as temperature $\theta$ and concentration $C$ at two consecutive time steps are less than $10^{-5}$ at all grid points.

For the type of boundary layer flow under consideration, the skin-friction, heat transfer coefficient and mass transfer coefficient are very important. Knowing the velocity field, the skinfriction at the vertical plate can be obtained, which in non-dimensional form is given by

$c_{f}=\left(\frac{\partial U}{\partial Y}\right)_{Y=0}$

Knowing the temperature field, the rate of heat transfer coefficient at the vertical plate can be obtained, which in non-dimensional form, in terms of the Nusselt number, is given by

$$
N u=\left(\frac{\partial \theta}{\partial Y}\right)_{Y=0}
$$

Knowing the concentration field, the rate of mass transfer coefficient at the vertical plate can be obtained, which in non-dimensional form, in terms of the Sherwood number, is given by

$S h=\left(\frac{\partial C}{\partial Y}\right)_{Y=0}$

The derivatives involved in Eqs. (17), (18) and (19) are evaluated using five point approximation formula.

\section{RESULTS AND DISCUSSION}

In order to get a physical insight into the problem, numerical computations are carried out to illustrate the effects of different governing parameters upon the 
nature of the flow and transport. The numerical values of the velocity, temperature, concentration, skin-friction, Nusselt number and Sherwood number are computed for different physical parameters like the exponent of the velocity of moving plate $a$, thermal Grashof number $G r$, mass Grashof number $G m$, magnetic parameter $M$, radiation parameter $R$, Prandtl number $P r$, heat generation/absorption parameter $\phi$, Schmidt number $S c$ and time $t$. A representative set of numerical results is shown graphically in Figs. 2-12. Here the value of $\mathrm{Pr}$ is chosen as 0.71 , which corresponds to air. The values of $S c$ are chosen such that they represent Helium (0.3), water vapour (0.6) and Ammonia (0.78). The other parameters are arbitrarily chosen.

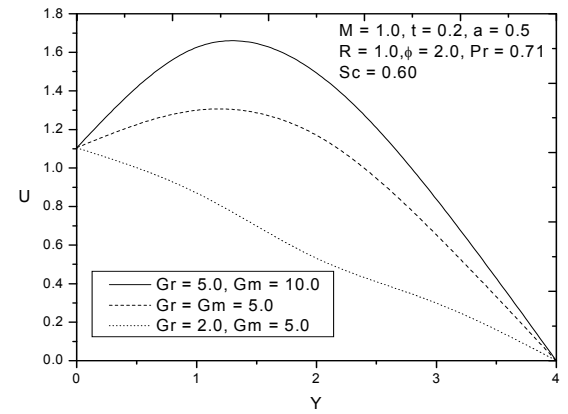

Fig. 2. Velocity profiles for different values of $\mathrm{Gr}$ and $\mathrm{Gm}$

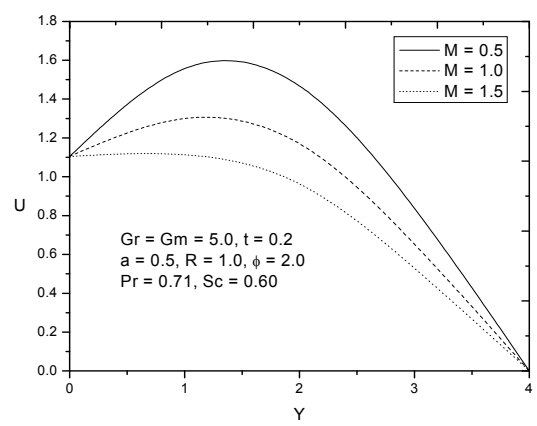

Fig. 3. Velocity profiles for different values of $M$

Figure 2 demonstrates the effects of different thermal Grashof number $G r$ and mass Grashof number $G m$ on the velocity. It is observed that the velocity increases with increasing values of the thermal Grashof number or mass Grashof number. The thermal Grashof number signifies the relative effect of the thermal buoyancy force to the viscous hydrodynamic force. The mass (solutal) Grashof number defines the ratio of the species buoyancy force to the viscous hydrodynamic force. The flow is accelerated due to the enhancement in buoyancy force corresponding to an increase in the thermal Grashof number i.e., free convection effects. The positive values of $\mathrm{Gr}$ correspond to cooling of the plate by natural convection. Heat is therefore conducted away from the vertical plate into the fluid which increases the temperature and thereby enhances the buoyancy force.

The effect of magnetic field parameter $M$ on the velocity is shown in Fig. 3. The velocity decreases with an increase in the magnetic parameter. It is because that the application of transverse magnetic field will result a resistive type force (Lorentz force) similar to drag force which tends to resist the fluid flow and thus reducing its velocity. Also, the boundary layer thickness decreases with an increase in the magnetic parameter.

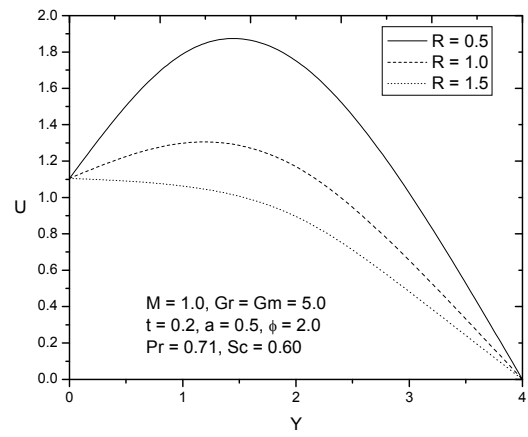

Fig. 4a. Velocity profiles for different values of $\mathrm{R}$

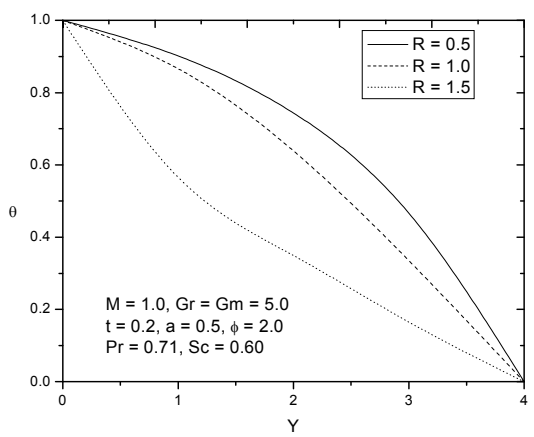

Fig. 4b. Temperature profiles for different values of $\mathrm{R}$

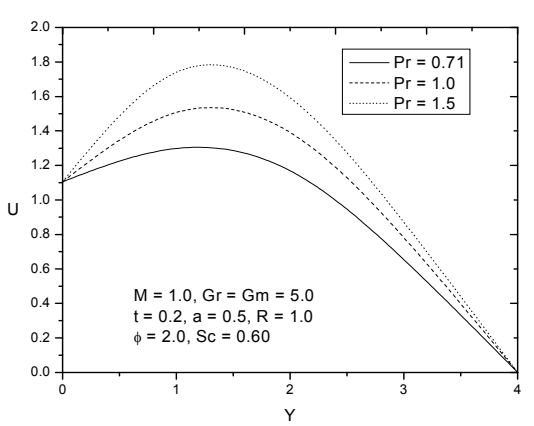

Fig. 5a. Velocity profiles for different values of $\mathrm{Pr}$

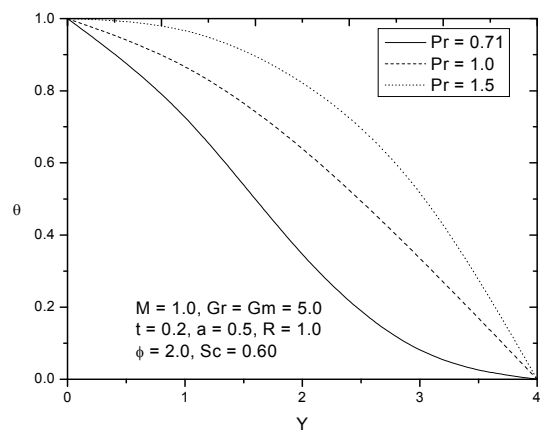

Fig. 5b. Temperature profiles for different values of $\operatorname{Pr}$

The influence of the thermal radiation parameter $\mathrm{R}$ on the velocity and temperature are shown in Figs. 4a and $4 \mathrm{~b}$ respectively. The radiation parameter $R$ 
defines the relative contribution of conduction heat transfer to thermal radiation transfer. It is obvious that an increase in the radiation parameter results in decreasing velocity and temperature within the boundary layer.

Figures $5 \mathrm{a}$ and $5 \mathrm{~b}$ show the effect of $\operatorname{Pr}$ on the transient velocity and temperature distributions. Both the velocity and temperature decrease as Pr increases. This is in agreement with the physical fact that the thermal boundary layer thickness decreases with increasing Pr.

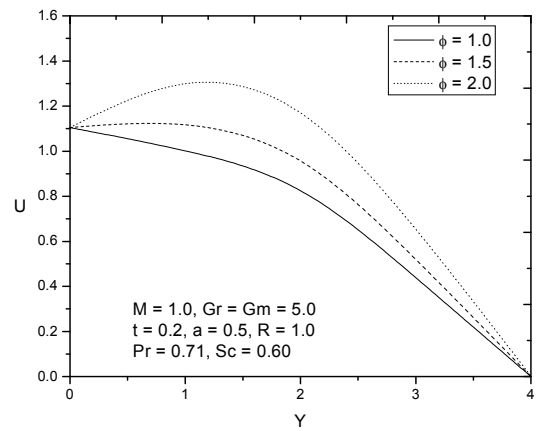

Fig. 6a. Velocity profiles for different values of $\phi$

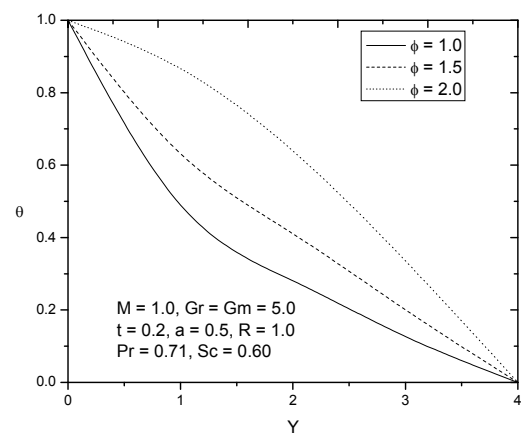

Fig. 6b. Temperature profiles for different values of $\phi$

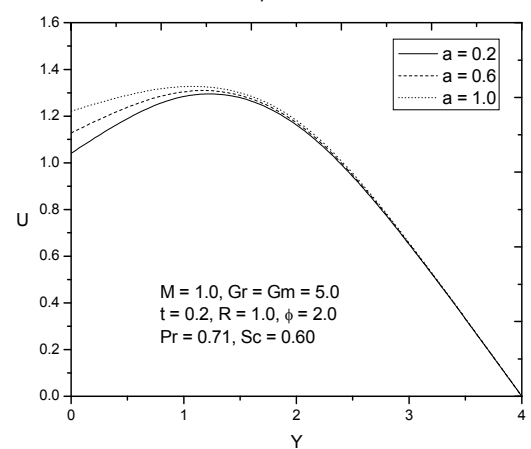

Fig.7. Velocity profiles for different values of $a$

The presence of a heat source in the boundary layer generates energy, which causes the temperature of the fluid to increase. This increase in temperature produces an increase in the flow field due to the buoyancy effect. These behaviors are evident from Figs. 6a and 6b.

The behavior of velocity for different values of the exponent of the velocity of moving plate ' $a$ ' and $t$ are presented in Figs. 7 and 8 respectively. It is observed that the velocity increases with increasing values of the exponent of the velocity of moving plate ' $a$ '. It is noticed that the velocity increases with increasing values of $t$.

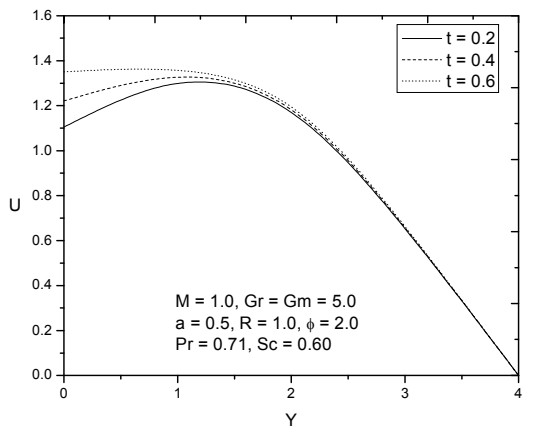

Fig. 8. Velocity profiles for different values of $t$

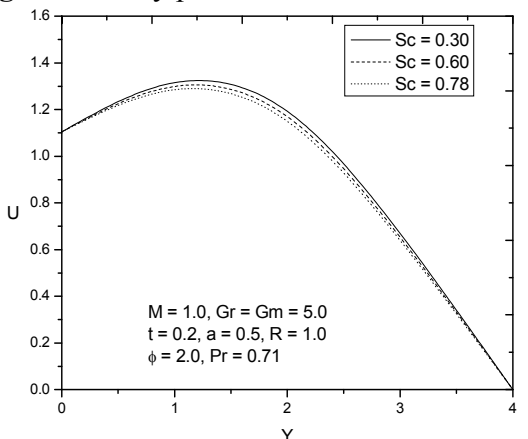

Fig. 9a. Velocity profiles for different values of $S c$

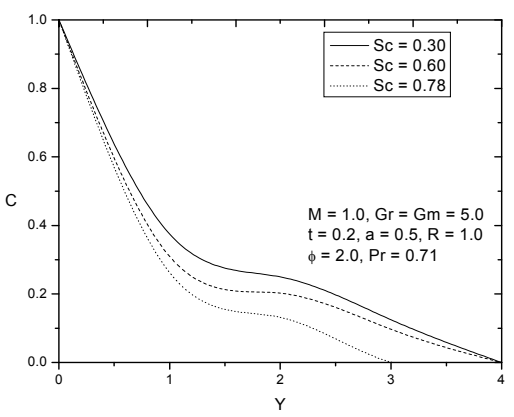

Fig. 9b. Concentration profiles for different values of Sc

For different values of the Schmidt number $S c$, the velocity and concentration profiles are plotted in Figs. 9a and $9 \mathrm{~b}$ respectively. The Schmidt number $S c$ embodies the ratio of the momentum diffusivity to the mass (species) diffusivity. It physically relates the relative thickness of the hydrodynamic boundary layer and mass-transfer (concentration) boundary layer. As the Schmidt number increases the concentration decreases. This causes the concentration buoyancy effects to decrease yielding a reduction in the fluid velocity. The reductions in the velocity and concentration profiles are accompanied by simultaneous reductions in the velocity and concentration boundary layers, which is evident from Figs. 9a and 9b.

The effects of various governing parameters on the skin-friction coefficient $C_{f}$, Nusselt number $N u$ and the Sherwood number $S h$ are shown in Tables 1, 2 and 3 . From these tables it is observed that the skin- 
friction increases as M or $G r$ or $G m$ or $a$ or $t$ or $R$ or $\operatorname{Pr}$ increases, while it decreases as $\phi$ increases. It is noticed that the Nusselt number increases in the presence of radiation or as $P r$ increases, while it decreases as $\phi$ increases. It is found that the Sherwood number increases as the Schmidt number increases.

Table 1 Numerical values of the skin-friction coefficient $C_{f}$ for $\mathrm{R}=1.0, \phi=2.0, \operatorname{Pr}=0.71$ and

\begin{tabular}{|c|c|c|c|c|c|}
\multicolumn{7}{c|}{$S c=0.6}$. \\
$M$ & $G r$ & $G m$ & $a$ & $t$ & $C_{f}$ \\
& & & & & \\
\hline 1.0 & 2.0 & 2.0 & 0.5 & 0.2 & 1.85825 \\
2.0 & 2.0 & 2.0 & 0.5 & 0.2 & 1.96886 \\
1.0 & 3.0 & 2.0 & 0.5 & 0.2 & 2.06459 \\
1.0 & 2.0 & 3.0 & 0.5 & 0.2 & 1.81317 \\
1.0 & 2.0 & 2.0 & 1.0 & 0.2 & 2.08287 \\
1.0 & 2.0 & 2.0 & 0.5 & 0.5 & 2.20388 \\
& & & & & \\
\hline
\end{tabular}

Table 2 Numerical values of

$C_{f}$ and $N u$ for $G r=2.0, G m=2.0$,

\begin{tabular}{|c|c|c|c|c|}
\hline \multicolumn{1}{|c|}{$M=1.0, t=0.2, a=0.5$ and $S c=0.6}$. \\
$R$ & $\phi$ & $\operatorname{Pr}$ & $C_{f}$ & $N u$ \\
\hline 1.0 & 2.0 & 0.71 & 1.85825 & 1.06156 \\
2.0 & 2.0 & 0.71 & 1.93250 & 1.55025 \\
1.0 & 3.0 & 0.71 & 1.00996 & -0.13466 \\
1.0 & 2.0 & 1.0 & 1.81217 & 0.68211 \\
\hline
\end{tabular}

Table 3 Numerical values of $C_{f}$ and $S h$ for $G r=2.0, G m=2.0, M=1.0, t=0.2, a=0.5$, $R=1.0, \phi=2.0$ and $\operatorname{Pr}=0.71$.

\begin{tabular}{|c|c|c|}
\hline$S c$ & $C_{f}$ & $S h$ \\
\hline 0.3 & 1.43598 & 1.83814 \\
0.6 & 1.44203 & 1.84005 \\
0.78 & 1.44709 & 1.84275 \\
\hline
\end{tabular}

\section{CONCLuSions}

The interaction of radiation with mass transfer past an accelerated isothermal vertical plate with uniform mass diffusion in the presence of magnetic field and heat source has been studied. The effects of thermo physical parameters on velocity, temperature and concentration are analyzed and the following observations were noticed. An increase in the radiation parameter results in decreasing velocity and temperature within the boundary layer. Increasing magnetic parameter decreases the velocity. With the increase of $\mathrm{Pr}$, the velocity and temperature profiles decrease. The presence of heat source raises the temperature. The skin-friction increases as $\mathrm{M}$ or $\mathrm{Gr}$ or $G m$ or $\mathrm{R}$ or $P r$ increases, and it decreases as $\phi$ increases. The Nusselt number increases as $\mathrm{R}$ or $\mathrm{Pr}$ increases, and it decreases as $\phi$ increases.

\section{REFERENCES}

Basant, K.J., R. Prasad and S. Rai (1991). Mass transfer effects on the flow past an exponentially accelerated vertical plate with constant heat flux. Astrophysics and Space Science 81, 125-134.

Chamkha, A.J. (1997). Non- Darcy fully developed mixed convection in a porous medium channel with heat generation/absorption and hydromagnetic effects. Numer. Heat Transfer 32, 853-875.

Das, U.N., R.K. Deka and V.M. Soundalgekar (1996). Radiation effects on flow past an impulsively started vertical infinite plate. $J$. Theo. Mech.1, 111-115.

Eckert, E.R. and R.M. Drake. (1972). Analysis of Heat and Mass Transfer.

Elbashbeshy, E.M.A. (1997). Heat and Mass Transfer along a vertical plate with variable surface tension and concentration in the presence of the magnetic field. Int. J. Engineering Science 34(5), 515-522.

Gebhart, B., Y. Jaluria, R.L. Mahajan and B. Sammakia (1998). Buoyancy induced flow and transport. New York Hemisphere.

Gebhart, B. and L. Pera (1971). The nature of vertical natural convection flows resulting from the combined buoyancy effects of thermal and mass diffusion. Int. J. Heat Mass Transfer 14, 2025-2050.

Gribben, J. (1965). The magneto hydrodynamic boundary layer in the presence of a pressure gradient. Proc. Royal. Soc. London A 287, 123141.

Gupta, A.S., I. Pop and V.M. Soundalgekar (1979). Free convection effects on the flow past an accelerated vertical plate in an incompressible dissipative fluid. Rev. Roum. Sci. Techn. Mec. Apl. 24, 561-568.

Helmy, K.A. (1998). MHD Unsteady free convection flow past a vertical porous plate. ZAMM 78, 255-270.

Hossain, M.A. and H.S. Takhar (1996). Radiation effects on mixed convection along a vertical plate with uniform surface temperature. Heat and Mass Transfer 31, 243-248.

Kafousias, N.G. and A.A. Raptis (1981). Mass transfer and free convection effects on the flow past an accelerated vertical infinite plate with variable suction or injection. Rev. Roum. Sci. Techn. Mec. Apl. 26, 11-22.

Kim, Y.J. (2000), Unsteady MHD convective heat transfer past semi-infinite vertical porous 
moving plate with variable suction. Int. J. Eng. Sci. 38, 833-845.

Mathers, W.G., A.J. Madden and E.L. Piret (1957). Simultaneous heat and mass transfer in free convection. Indian. Engg. Chem. 49, 961-968.

Muthucumaraswamy, R. and Janakiraman (2006). MHD and Radiation effects on moving isothermal vertical plate with variable mass diffusion. Theoret. Appl. Mech. 33(1), 17-29.

Muthucumaraswamy, R., K.E. Sathappan and R. Natarajan (2008). Mass transfer effects on exponentially accelerated isothermal vertical plate. Int. J. of Appl. Math. and Mech. 4(6), 1925.

Pop, I. and V.M. Soundalgekar (1962). Viscous dissipation effects on unsteady free convective flow past an infinite vertical porous plate with variable suction. I. J. Heat Mass transfer 17, 8592.

Ramachandra Prasad, V., N. Bhaskar Reddy and R. Muthucumaraswamy (2006). Finite difference analysis of radiation effects on MHD free convection flow with mass transfer past a semiinfinite vertical plate in the presence of heat source/sink. International Review of Pure and Applied Mathematics 2(2), 41-160.

Ramachandra Prasad, V., N. Bhaskar Reddy and R. Muthucumaraswamy (2007). Radiation and Mass Transfer Effects on Two-Dimensional Flow past an impulsively started isothermal vertical plate. Int. J. of Thermal Sciences 46(12), 1251-1258.

Raptis, A. and C. Perdikis (1999). Radiation and free convection flow past a moving plate. Int. J. of App. Mech. and Engg. 4, 817-821.

Sahoo, P.K., N. Datta and S. Biswal (2003). MHD unsteady free convection flow past an infinite vertical plate with constant suction and heat sink. Indian Journal of Pure and Applied Mathematics 34(1), 145-155.

Singh, A.K. and Naveen Kumar (1984). Free convection flow past an exponentially accelerated vertical plate. Astrophysics and Space Science 98, 245-258.

Somers, E.V. (1956). Theoretical considerations of combined thermal and mass transfer from vertical flat plate. J. Appl. Mech., 295-301.

Suneetha, S., N. Bhaskar Reddy and V. Ramachandra Prasad (accepted). Investigated radiation and mass transfer effects on MHD free convective dissipative fluid in the presence of heat source/ sink. JAFM, (to appear in JAFM).
Soundalgekar, V.M. and P. Ganesan (1981). FiniteDifference analysis of transient free convection with mass transfer on an isothermal vertical flat plate. Int. J. Engg. Sci. 19, 757-770.

Soundalgekar, V.M. and H.S. Takhar (1993). Radiation effects on free convection flow past a semi-infinite vertical plate. Modeling, Measurement and control B51, 31-40.

Takhar, H.S., C.D. Surma Devi, and G. Nath (1986). Heat and Mass Transfer for a point sink in a plane with a magnetic field. Mechanics Research Communications 13, 71-78.

Vajravelu, K. and A. Hadjinicolaou (1993). Heat transfer in a viscous fluid over a stretching sheet with viscous dissipation and internal heat generation. Int. Commun. Heat Mass Transfer 20, 417-430. 